\title{
ARTÍCULOS
}

\section{UNA HISTORIA DE CORRUPCIÓN Y DESFALCO: EL RESCATE DEL BERGANTÍN NUESTRA SEÑORA DEL CARMEN Y SAN JOSÉ EN LAS COSTAS DE TABASCO (1705-1706).}

\author{
Carlos Moreno Amador \\ Universidad de Sevilla \\ carlosmoreno@us.es
}

Resumen: Este trabajo centra su atención en el naufragio del bergantín Nuestra Señora del Carmen y San José a finales de 1705 y en las irregulares actuaciones llevadas a cabo desde la alcaldía mayor tabasqueña en la gestión del cargamento recuperado tras su hundimiento. El barco, que se dirigía desde el puerto de San Cristóbal de La Habana hasta Veracruz, zozobró en costas tabasqueñas, concretamente en un lugar llamado Quebrada Grande, entre la barra de Tabasco y la de Chiltepec, después de haberse desviado al puerto de San Francisco de Campeche para arreglar los graves desperfectos que había sufrido debido a las malas condiciones climatológicas. La controvertida actuación del alcalde mayor y sus subalternos en el rescate de los géneros que transportaba la embarcación y el posterior desvío fraudulento de parte de esa mercancía con fines lucrativos privados provocó las quejas de una buena parte de la población tabasqueña. En el juicio de residencia del alcalde mayor, Alonso Felipe Andrade, se llevó a cabo una minuciosa investigación por la gestión de dicho rescate, aspecto que analizaremos con detenimiento en el artículo.

Palabras clave: Nuestra Señora del Carmen y San José, bergantín, naufragio, Tabasco, historia marítima, expolio, abuso de poder, siglo XVIII.

Tittle: A HISTORY OF CORRUPTION AND EMBEZZLEMENT: THE RESCUE OF THE SHIP NUESTRA SEÑORA DEL CARMEN Y SAN JOSÉ ON THE COASTS OF TABASCO (17051706).

Abstract: This article focuses on the shipwreck of the brigantine Nuestra Señora del Carmen and San José at the end of 1705 and the irregular actions carried out by the governor of Tabasco in the management of the cargo recovered after the sinking. The ship, which was heading from the port of San Cristóbal de La Habana to the port of Veracruz, sank on Tabasco's coast, in a place called Quebrada Grande, after having diverted to the port of San Francisco de Campeche to repair the serious damage that it had suffered due to bad weather conditions. The controversial action of the governor and his subordinates in the rescue of the cargo carried by the brigantine and the subsequent fraudulent deviation of part of that merchandise for private lucrative purposes provoked the complaints of a part of the Tabasco population. In the residence of the mayor, Alonso Felipe Andrade, a thorough investigation was carried out for the management of said rescue, an aspect that we will analyze carefully in the following article.

Recibido: 23-03-2020

Aceptado: $26-03-2020$

Cómo citar este artículo: MORENO AMADOR, Carlos. Una historia de corrupción y desfalco: el rescate del bergantín Nuestra Señora del Carmen y San José en las costas de Tabasco (1705-1706). Naveg@mérica. Revista electrónica editada por la Asociación Española de Americanistas [en línea]. 2020, n. 24. Disponible en: <http://revistas.um.es/navegamericas. [Consulta: Fecha de consulta]. ISSN 1989-211X. 
Keywords: Nuestra Señora del Carmen y San José, brigantine, shipwreck, Tabasco, maritime history, plunder, abuse of authority, $18^{\text {th }}$ century.

\section{Introducción}

Son infinitas las referencias documentales que recoge la historiografía americanista relativas a naufragios de barcos en el Golfo de México a lo largo del periodo colonial. Y es que el importante volumen de navíos que circunnavegaron la zona durante los más de tres siglos de dominación española, unido a las especiales condiciones de inestabilidad meteorológica de la región Golfo de México-Caribe en determinados momentos del año, principalmente en el periodo agosto-noviembre, provocaron un sinfín de hundimientos a lo largo de los años ${ }^{1}$.

\section{Resulta evidente, tal y como lo expresa Romero Castaño y Pérez Díaz, que:}

"La navegación, como toda gran empresa, afrontó riesgos y accidentes en los que se perdieron muchas vidas, mercancías, artefactos, esperanzas y embarcaciones, quedando todo bajo el agua. Los naufragios coloniales fueron el resultado de una actividad mercantil y de particulares intensiva propia de los intereses monárquicos y comerciales de las coronas europeas de ese periodo. Esos accidentes navales son considerados como cápsulas del tiempo, por cuanto encierran la historia de un barco en particular, pero estas naves también están asociadas a actividades sociales, económicas e incluso simbólicas que brindan información sobre la forma de vida en las embarcaciones, los circuitos comerciales y la tecnología de la época, entre otros"2.

Los especialistas en la temática apuntan varios motivos como las principales causas de los desastres marítimos acaecidos a consecuencia del tráfico comercial indiano. El primero de ellos estaría en relación con el medio natural; las condiciones climatológicas adversas, materializadas en temporales, suponían a veces obstáculos imposibles de salvar para los bajeles castellanos.

\footnotetext{
1 Son muchas las obras que dedican su atención al registro y catalogación de naufragios acaecidos en las colonias españolas durante el periodo colonial. Una de las más importantes es la de Robert $\mathrm{F}$. Marx, Shipwrecks in the Americas, donde se incluye una lista de más de 4.000 naufragios organizados por año y localización del suceso; MARX, Robert F. Shipwrecks in the Americas. Nueva York: Dover Publications, 1987. Por su parte, Cesáreo Fernández plantea un estudio muy interesante sobre naufragios de la Armada española, durante los siglos XVIII y XIX, registrados en el Archivo del Ministerio de Marina, donde recoge no solamente referencias de los siniestros marítimos, sino también una relación de los jefes oficiales fallecidos en dichos naufragios; FERNÁNDEZ DURO, Cesáreo. Naufragios de la Armada Española. Sevilla: Editorial Renacimiento, 2009. El resto de potencias europeas con presencia en América tampoco estuvieron exentas de sufrir los avatares de la mar, hecho bien documentado por diversos autores especialistas en la temática. Para el caso portugués, por ejemplo, disponemos, entre muchos, del relato de António Sérgio sobre los naufragios de navíos portugueses durante la época de las conquistas SÉRGIO, António. História trágicomarítima. Narrativas de naufragios da época das conquistas. Lisboa: Sá da Costa Editora, 2008.

${ }^{2}$ GOULD, Richard A. Archaeology and the social history of ships. Cambridge: Cambridge University Press, 2000; cit. por: ROMERO CASTAÑO, Luis René y PÉREZ DÍAZ, Juan Felipe. Naufragios y puertos marítimos en el Caribe Colombiano. México: Siglo Veintiuno Editores, 2005, p. 12.
} 
El segundo, centrado en las propias trabas que ofrecía el litoral, que provocaban en ocasiones la zozobra de las flotas ante el desconocimiento del medio por parte de los navegantes 0 , simplemente, por la negligencia o incompetencia de estos, que podía comportar errores de cálculo en cuanto al rumbo tomado. Sin embargo, la imprudencia podía, en ocasiones, verse complementada también por la mala fortuna, ya que cualquier contrariedad experimentada en la climatología, por pequeña que fuese, era susceptible de derivar en un siniestro náutico. El hecho de verse inmersos en alguna tempestad a veces escapaba de la responsabilidad de los administradores de los navíos, sobre todo cuando decidían hacerse a la mar en épocas favorables para la navegación. Incluso, en ocasiones los desplazamientos en épocas menos recomendables estaban motivados por imperativos ajenos a sus intereses, por las propias necesidades del comercio o por injerencias externas, lo que también en parte eximía de culpa a los responsables de las flotas ${ }^{3}$.

Otro aspecto a tener en cuenta es el planteado por Serrano Mangas, quien afirma que la pérdida de calidad y falta de formación que los pilotos, marineros y comandantes sufrieron a lo largo del tiempo también originó un importante número de accidentes, considerando los abundantes casos de incompetencia registrados durante la Carrera de Indias ${ }^{4}$.

Las investigaciones oficiales llevadas a cabo por las autoridades acerca de los naufragios en América confirman los anteriores planteamientos, pues ofrecen un claro panorama sobre las causas más comunes de dichas catástrofes, que tienen que ver, precisamente, con la falta de tripulantes expertos e instruidos, los errores de apreciación de los pilotos, los problemas de sobrecarga, las deficiencias en las carenas y, por supuesto, las inclemencias marítimas y climatológicas ${ }^{5}$.

El caso de estudio de este artículo, el siniestro del bergantín Nuestra Señora del Carmen y San José en las costas de Tabasco a finales de octubre de 1705, estuvo condicionado por varios de los factores que acabamos de referir: las malas condiciones climatológicas que presentaba el mar, unido a una más que posible mala elección en cuanto a la época del año en que se decidió realizar el viaje (los marineros eran conocedores de la violencia con que se comportaban los vientos del norte en el Golfo de México desde finales del verano y durante el otoño) ${ }^{6}$ y, probablemente, a una mala decisión tomada por el maestre del barco, motivaron que la embarcación zozobrase en aquellas tierras, tal y como veremos a continuación?.

\footnotetext{
${ }^{3}$ PEREZ-MALLAINA BUENO, Pablo Emilio. Naufragios en la Carrera de Indias durante los siglos XVI y XVII. El hombre frente al mar. Sevilla: Editorial Universidad de Sevilla, 2015, p. 87; SERRANO MANGAS, Fernando. Naufragios y rescates en el tráfico indiano en el siglo XVII. España: Ediciones Siruela, 1991, p. 29.

${ }^{4}$ SERRANO MANGAS, Fernando. Naufragios y rescates... Op. cit., p. 32.

5 PEREZ-MALLAINA BUENO, Pablo Emilio. Naufragios en la Carrera... Op. cit., p. 92.

${ }^{6}$ MORENO AMADOR, Carlos. Gobernar bajo sospecha. Estrategias del poder y prácticas corruptas en la alcaldía mayor de Tabasco (1660-1716). Sevilla: Editorial Universidad de Sevilla; Diputación de Sevilla; Consejo Superior de Investigaciones Científicas, 2018, p. 32; PEREZ-MALLAINA BUENO, Pablo Emilio. Naufragios en la Carrera... Op. cit., p. 92.

7 Los naufragios en las costas de Tabasco, principalmente por sus condiciones geoclimáticas, fueron frecuentes desde fechas muy tempranas. Haring, por ejemplo, hace referencia a que en esa zona "perecieron cuatro naves de la flota de Nueva España en 1571 y cinco más en 1572"; HARING, Clarence Henry. Comercio y navegación entre España y las Indias en la época de los Habsburgos.
} 
El accidente y su posterior rescate generaron un importante debate en torno a la controvertida y parcial gestión de su cargamento a manos de las autoridades tabasqueñas, hecho que analizaremos con detenimiento. Las quejas de los vecinos en el juicio de residencia del alcalde mayor Alonso Felipe de Andrade, máximo responsable de la provincia en aquel entonces, dieron lugar a un interesante expediente relativo al naufragio y a la recuperación de los géneros del bergantín base para nuestro trabajo-, el cual nos servirá para poder reconstruir el fallido viaje realizado por el bajel y saber cómo se organizó el rescate de su cargamento. A su vez, nos permitirá conocer cuál fue el proceder del alcalde mayor, cómo se apropió indebidamente de una parte de la mercancía del pecio, y cómo ordenó su desvío a otras regiones de forma fraudulenta a través de diversos testaferros. La sentencia de residencia de Andrade nos servirá, igualmente, para averiguar las consecuencias que tuvieron, este y sus subalternos, debido a la manera en que actuaron y gestionaron la situación.

\section{El naufragio del bergantín Nuestra Señora del Carmen y San José}

El 14 de septiembre de 1705, el capitán Andrés González Fonseca, administrador y maestre del bergantín Nuestra Señora del Carmen y San José, solicitó licencia de viaje a los oficiales de la Real Hacienda de La Habana para viajar desde el puerto de San Cristóbal hasta el de Veracruz con el fin de transportar algunos frutos de la tierra. Ese mismo día las autoridades competentes, tras la revisión pertinente del barco por parte de los maestros mayores de carpintería y calafatería del puerto, le concedieron dicha licencia para realizar la travesía. Un día después comenzaba los preparativos, presentando como fiador a Juan de Justis ${ }^{8} \mathrm{y}$, posteriormente, registrando el cargamento que los comerciantes le habían otorgado para realizar el transporte, compuesto principalmente por 146 sacos de tabaco en polvo de simonete y algo de tabaco en rama ${ }^{9}$. Finalmente, tras casi un mes de trámites, el 11 de octubre el bergantín zarpó de La Habana rumbo a su destino.

Sin embargo, la embarcación nunca llegaría a Veracruz. Las malas condiciones climatológicas que la tripulación sufrió durante el trayecto provocaron importantes daños en la estructura de la nave, motivo por el cual el piloto decidió dar media vuelta a la altura de Tabasco y poner rumbo al puerto de San Francisco de Campeche con el objetivo de encontrar el resguardo necesario para arreglar los desperfectos y hacer acopio de bastimentos antes de retomar el viaje. Pese a los esfuerzos por continuar la marcha -les llevó a arrojar al mar dos piezas de artillería para aligerar la carga- ${ }^{10}$, en la madrugada del 28 de octubre de 1705, el barco quedó

Ciudad de México: Fondo de Cultura Económica, 1979, p. 367.

${ }^{8}$ Según el testimonio del contramaestre de la embarcación, el verdadero dueño del navío era el propio Juan de Justis, quien había nombrado como piloto, maestre y administrador a don Andrés González Fonseca. Archivo General de Indias (en adelante AGI), Escribanía de cámara, 233B, Cuaderno I. Declaración de Francisco de los Ríos, contramaestre del bergantín, tras su rescate en Tabasco. Jalapa, 15 de noviembre de 1705.

${ }^{9} \mathrm{AGI}$, Escribanía de cámara, 233B, Cuaderno I. Auto de licencia y viaje concedido al capitán don Andrés González Fonseca. La Habana, 10 de octubre de 1705.

${ }^{10}$ Esta práctica resultaba muy frecuente. Pérez Mallaína hace referencia a que "echar al mar una parte pequeña del cargamento permitía aumentar la estabilidad de la embarcación y salvar la mayor parte del contenido de la bodega". PEREZ-MALLAINA BUENO, Pablo Emilio. Naufragios en la 
varado en las costas tabasqueñas, entre la barra de Tabasco y la de Chiltepec, concretamente en un lugar llamado la Quebrada Grande, apenas tres leguas a sotavento de la barra de Tabasco ${ }^{11}$.

El testimonio de uno de los marineros del navío, Juan Gómez, resume con bastante detalle la delicada situación por la que debieron pasar sus tripulantes:

"Se vieron sorprendidos por temporales y tormentas, de tal forma que en una les obligó a echar al agua dos piezas de artillería con sus carenas, así para aligerar la embarcación como porque la maltrataban en los costados, y temiéndose abriese dicho bergantín y la jarcia que tenían muy maltratada, que desconfiaron coger dicho puerto de la Veracruz y tiraban solo ya a escapar las vidas, yendo a varar con dicha embarcación. Y siguiendo este dictamen por todo y parecer de todos, tiraron la vuelta de tierra para ver si podían dar con un varadero. $Y$ en este tiempo calmó el viento y se aquietó la mar, con que mudaron de intención y se propuso arribar al puerto de San Francisco de Campeche para repararse así de bastimentos y aguado, que padecían mucha necesidad, como componerse y aliñar la embarcación. Y mudando rumbo tiraron la vuelta del leste cuarta nordeste en busca de la sonda de Campeche. Y el día 28 se hallaron varados sin pensar entre las dos barras de Tabasco y Chiltepeque"12.

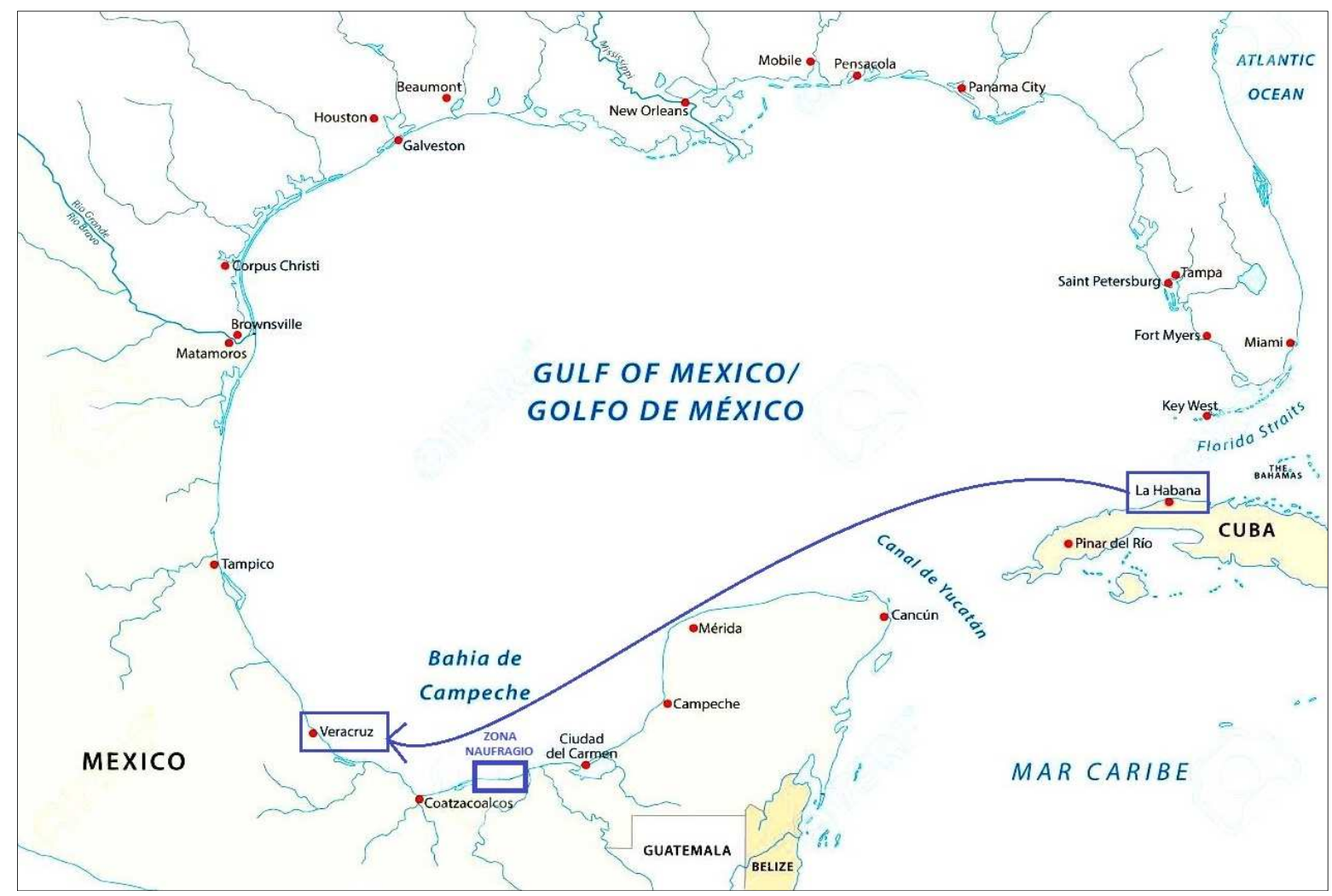

Mapa 1: Trayecto del barco Nuestra Señora del Carmen y San José y zona donde naufragó. Fuente: Elaboración propia.

Carrera... Op. cit., p. 133.

${ }^{11}$ AGI, Escribanía de Cámara, 233B, Cuaderno 1. Declaración de marineros sobre el naufragio del bergantín en Tabasco. Jalapa, 12-15 de noviembre de 1705.

12 AGI, Escribanía de cámara, 233B, Cuaderno I. Declaración de Juan Gómez, marinero del bergantín, tras su rescate en Tabasco. Jalapa, 13 de noviembre de 1705. 
Es posible que el piloto decidiese acercarse demasiado a la costa al poner rumbo a Campeche para poner a salvo el cargamento en caso de volver a encontrarse ante unas condiciones climatológicas adversas, corriendo el riesgo de dañar gravemente el casco del navío, como efectivamente sucedió ${ }^{13}$.

Un día después del siniestro, el 29 de octubre de 1705, Francisco Martín de Llanos, teniente de la barra de Tabasco, notificaba al alcalde mayor, Alonso Felipe de Andrade, el avistamiento de una embarcación varada en una ronda de reconocimiento por la costa, informándole de que volverían al día siguiente para intentar averiguar de qué nación era y si entrañaba peligro, teniendo en cuenta la continua y dañina presencia de enemigos piratas en las aguas de la región ${ }^{14}$. En esa tesitura, el gobernante tomó la determinación de enviar a su teniente en el partido de la Chontalpa, Juan Antonio Solano, para socorrer a la tripulación del barco y reconocer y registrar la mercancía que transportaba. Efectivamente, el 30 de octubre dispuso que saliesen una galeota y una piragua de guerra con cincuenta hombres cargados de armas, pertrechos y bastimentos, con la orden de que:

"Si fuesen españoles los socorriesen y procurasen salvar y librar toda la carga, y si eran enemigos los apresasen, pues se hallaban indefensos, quemasen la embarcación, porque el enemigo no se aprovechase de ella en ninguna manera"15.

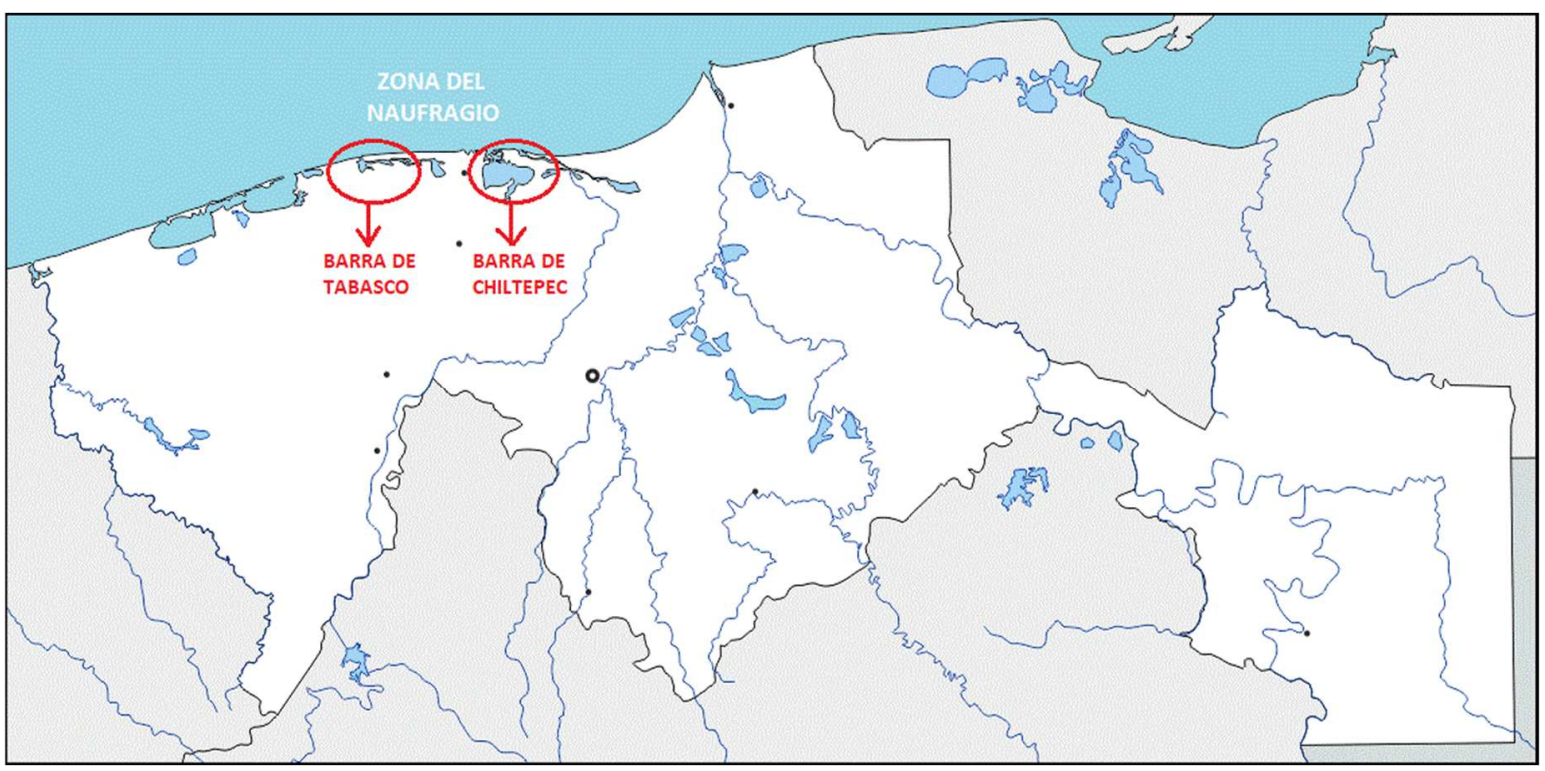

Mapa 2: Zona del naufragio del bergantín. Fuente: Elaboración propia.

${ }^{13}$ En estas situaciones primaba la máxima de sacrificar parte de la hacienda para salvar el resto. PEREZ-MALLAINA BUENO, Pablo Emilio. Naufragios en la Carrera... Op. cit., p. 133.

${ }^{14} \mathrm{La}$ actividad pirática en las costas tabasqueñas condicionó sobremanera la vida de la región, hasta el punto de requerirse una organización de vigilancia exhaustiva para intentar detectar la presencia de corsarios, filibusteros o piratas en la zona, frente al gravísimo daño que estos causaban con sus incursiones a través de los múltiples ríos navegables. Para un conocimiento más exhaustivo del tema puede consultarse la obra de EUGENIO MARTíNEZ, María Ángeles. La defensa de Tabasco, 16001717. Sevilla: Escuela de Estudios Hispanoamericanos, 1971.

${ }^{15}$ AGI, Escribanía de Cámara, 233B, Cuaderno 1. Auto del alcalde mayor don Alonso Felipe de Andrade sobre el naufragio del bergantín en Tabasco. Jalapa, 31 de octubre de 1705. 


\section{El rescate del navío por parte de las autoridades tabasqueñas}

El 1 de noviembre de 1705 partía desde Jalapa el contingente de rescate para cumplir con las directrices del alcalde mayor. Era imprescindible comprobar si la tripulación se encontraba a salvo y también recuperar y revisar el cargamento que llevaba el bergantín como parte del protocolo de actuación; por regla general, cuando acontecía un naufragio, el desorden y la confusión hacían acto de presencia: los propios marineros eran propensos a sustraer las riquezas que trasportaban los barcos en que navegaban, algo que se agravaba con la actitud que mostraban, en muchas ocasiones, los habitantes cercanos a las costas donde se producía el siniestro, acudiendo en masa con todos los medios de que disponían para saquear cuanto pudiesen ${ }^{16}$.

En esa situación, una rápida y eficaz intervención por parte de las autoridades competentes suponía la diferencia entre la recuperación total, o al menos parcial, de la mercancía y la completa pérdida de la misma. La Corona, a través de sus representantes en la zona, era la encargada de poner en marcha y gestionar el mecanismo de rescate. La misión de localizar los restos, desplazar las embarcaciones necesarias para llevar a cabo el recobro de los mismos, etc., recaía por tanto en ellos. Se trataba, en suma, de salvar el mayor volumen de productos y géneros en el menor tiempo posible, y recuperar todo aquello susceptible del pillaje de los merodeadores.

La explicación del protagonismo que la institución se atribuyó en los rescates se fundamenta, para Pérez Mallaína, esencialmente en dos causas. La primera y más evidente tiene que ver con los intereses de la Real Hacienda: el rey, en última instancia, era el mayor perjudicado cuando se producía un incidente náutico, pues las arcas del Estado se veían resentidas en mayor o menor medida; se entiende, por tanto, que intentase limitar al máximo la incidencia de los desastres organizando expediciones de salvamento para recuperar la parte que le correspondiera. La segunda estaría relacionada con el papel de la monarquía como órgano rector de la vida social en las Indias. Y es que, uno de los problemas más frecuentes después de un siniestro era averiguar a quién pertenecían los bienes rescatados, sobre todo en lo relativo a las mercancías; era normal que los dueños de los barcos y sus fiadores o aseguradores iniciasen un conflicto para dirimir la propiedad de dichos restos. En ese sentido, el enfrentamiento suponía poco más que una alteración del orden social a costa del sentido de la propiedad, motivo por el que la Corona, tanto en sus territorios indianos como en la propia Península, se sintiera en la obligación de restituir el equilibrio dirigiendo los rescates y la devolución de los bienes recuperados a través de sus funcionarios e incluso, en ocasiones, mediante asientos firmados con particulares para que se encargasen de todo lo relativo a dicha empresa ${ }^{17}$. En las costas americanas eran los gobernadores locales los máximos responsables de

\footnotetext{
${ }^{16}$ SERRANO MANGAS, Fernando. Naufragios y rescates... Op. cit., p. 39.

17 PEREZ-MALLAINA BUENO, Pablo Emilio. Naufragios en la Carrera... Op. cit., pp. 115-120; SERRANO MANGAS, Fernando. Naufragios y rescates... Op. cit., p. 55. Un buen ejemplo de este tipo de asientos lo encontramos en el artículo de PAJUELO MORENO, Vicente. Naufragio y rescate de la flota y armada del marqués del Vado del Maestre, 1691. Anuario de Estudios Americanos. Ene./Jun. 2019, vol. 76, n. 1, pp. 155-175.
} 
controlar y organizar los trabajos de recuperación de los pecios hundidos o varados. En ocasiones estos solían delegar las acciones de supervisión en los oficiales de la Real Hacienda, aunque era frecuente también que se lo encargasen a personas de confianza, familiares o paniaguados ${ }^{18}$.

Dicha determinación fue la que tomó, precisamente, el alcalde mayor en el caso que nos ocupa. El 3 de noviembre de 1705, apenas tres días después de haber recibido las órdenes de Alonso Felipe de Andrade, el teniente de la Chontalpa y el resto de subalternos encargados del rescate del bergantín Nuestra Señora del Carmen y San José llegaban a la costa y localizaban a los marineros y oficiales de la nao, que habían sido auxiliados en primera instancia por el vigía de la barra ante la escasez de agua y bastimentos con que contaban. Después de dar parte de la situación en que se encontraba el navío y de realizar un registro de los pertrechos, armas, municiones y mercaderías que se habían salvado del naufragio, con la teórica intención de enviar a Veracruz las partidas registradas oficialmente en La Habana, todo el cargamento fue trasladado hasta el almacén de las casas reales del pueblo de Jalapa por el cabo de la galeota de Tabasco y teniente de dicha villa, Archibaldo Magdonel. Para tal fin se desplazó con la galeota y cuatro piraguas pertenecientes a los pueblos de Astapa, Jaguacapa y Jalapa, acompañado de un contingente de medio centenar de hombres a su servicio ${ }^{19}$.

Una vez en Jalapa, tras haber tomado declaración al maestre y administrador del barco, Andrés González Fonseca, al contramaestre, Francisco de los Ríos, y a media docena de marineros que viajaban con ellos, ${ }^{20}$ las autoridades solicitaron a dicho maestre el registro de las mercancías que traía en la licencia que había obtenido en La Habana. Una vez revisado, siendo conscientes de que estaban transportando géneros prohibidos (el registro solamente contenía tabaco), el alcalde mayor ordenó realizar un inventario de todos los bienes rescatados por sus oficiales, cuyo resultado fue el siguiente:

\begin{tabular}{|l|c|}
\hline \multicolumn{1}{|c|}{ GÉNERO } & CANTIDAD \\
\hline Rejas de arar (con costra por haberse mojado) & 470 \\
\hline $\begin{array}{l}\text { Clavazón (18 sacos de escora y media escora, } \\
\text { también con costra por estar mojados) }\end{array}$ & 32 quintales \\
\hline Hierro (con costra) & 200 quintales (en 400 barras) \\
\hline Herraduras (inservibles por haberse mojado) & 173 docenas \\
\hline Papel & 40 resmas \\
\hline Botijuelas de aceite & 10 \\
\hline Aguardiente & 12 pipas (muy maltratadas de golpes) \\
\hline Tabaco en polvo & 18 sacos \\
\hline
\end{tabular}

Tabla 1: Inventario de géneros rescatados del bergantín por Alonso Felipe de Andrade. Fuente: Elaboración propia en base a los datos consultados en $\mathrm{AGI}^{21}$.

18 PEREZ-MALLAINA BUENO, Pablo Emilio. Naufragios en la Carrera... Op. cit., p. 126.

19 AGI, Escribanía de Cámara, 233B, Cuaderno 1. Diligencias realizadas para el rescate del bergantín. Jalapa, 3 de noviembre de 1705.

${ }^{20}$ AGI, Escribanía de Cámara, 233B, Cuaderno 1. Declaración de marineros sobre el naufragio del bergantín en Tabasco. Jalapa, 12-15 de noviembre de 1705.

${ }^{21}$ AGI, Escribanía de Cámara, 233B, Cuaderno 1. Inventario de los géneros rescatados del bergantín que naufragó en las costas de Tabasco. Jalapa, 16 de noviembre de 1705. 
El resultado del inventario no dejaba lugar a dudas. La mayor parte de las mercancías rescatadas no aparecían registradas en la licencia, algo que tampoco debe sorprendernos, habida cuenta de que el contrabando en el comercio indiano fue muy frecuente casi desde el comienzo de la Carrera de Indias pese a la amplia legislación dictada a lo largo de los años en pos de evitar el fraude ${ }^{22}$. En palabras de Pérez-Mallaína, "pocos de los mejores marinos del siglo XVI se libraron de acusaciones y pleitos por motivos más o menos parecidos, y a más de un capitán general de la Armada de la Guarda se le encontraron en su camarote talegos enteros llenos de doblones de contrabando"23. La excusa que utilizó el maestre para justificar el transporte de géneros sin registrar fue la de alegar que se los "embarcaron algunos pasajeros que vinieron de España en un navío que entró de Vizcaya en dicho puerto [de La Habana]"24.

\section{La controvertida gestión del cargamento}

Viendo que gran parte de los productos inventariados carecían de registro ${ }^{25}$ y además se encontraban entre los prohibidos para comerciar "puerto a puerto" en las Indias, el 17 de noviembre el alcalde mayor tomó la determinación de rematarlos en pública almoneda, asignando a la Real Hacienda una tercera parte de lo que se obtuviese en la subasta. Los 18 sacos de tabaco que contaban con partida de registro se salvaban de dicho remate, pues debían ser enviados por ley a sus legítimos dueños en Veracruz (Agustín de Palomino y don Blas Pérez, vecinos de dicha villa) en la primera embarcación que partiese hacia allí, a donde iban dirigidos y consignados desde La Habana ${ }^{26}$. Después de cuatro pregones, finalmente, el día 28 de ese mismo mes se llevó a cabo el remate de todos los géneros confiscados. Tras una primera puja de Pedro de Ojeda, fue el capitán don Diego Cervantes, vecino de Jalapa, quien ofreció una mayor cantidad de dinero por dichos efectos. En concreto, en su puja:

"Sin embargo de los defectos y averías que padecen dichos géneros daba y pagaba en contado lo que montase el entrego, a 130 pesos la pila de aguardiente, 11 pesos el quintal de clavazón, 12 reales por cada reja, a 6 pesos por cada resma de papel, a 10 pesos por cada quintal de hierro, 5 pesos por cada botija de

\footnotetext{
${ }^{22}$ Recopilación de Leyes de los Reinos de las Indias. Madrid: Boix, 1841, Libro IX, título 33, De los registros.

${ }^{23}$ PEREZ-MALLAINA BUENO, Pablo Emilio. Naufragios en la Carrera... Op. cit., pp. 129-130.

${ }^{24}$ AGI, Escribanía de cámara, 233B, Cuaderno I. Declaración de Andrés González de Fonseca, maestre del bergantín, tras su rescate en Tabasco. Jalapa, 15 de noviembre de 1705.

25 Los propios marineros reconocieron en sus declaraciones el transporte de productos no registrados, como barras de hierro, pipas de aguardiente, cajones de clavazón, resmas de papel o aceite. AGI, Escribanía de Cámara, 233B, Cuaderno 1. Declaración de marineros sobre el naufragio del bergantín en Tabasco. Jalapa, 12-15 de noviembre de 1705.

${ }^{26} \mathrm{AGI}$, Escribanía de Cámara, 233B, Cuaderno 1. Auto de descamino de los géneros del bergantín que naufragó en Tabasco. Jalapa, 17 de noviembre de 1705. El 8 de diciembre de 1705 el alcalde mayor notificaba a Andrés González la obligación de ajustarse con el maestre Miguel Alfonso del Manzano, quien se disponía a hacer un viaje al puerto de Veracruz, para que transportase en su balandra los 18 sacos que tenía registrados en su licencia, apercibiéndole de que los gastos debían correr por su cuenta y riesgo; AGI, Escribanía de Cámara, 233B, Cuaderno 1. Auto para el maestre Andrés González acuerde el envío del tabaco registrado en su licencia hasta Veracruz. Jalapa, 8 de diciembre de 1705.
} 
aceite y a 6 reales la docena de herraduras" 27 .

El montante total que debió pagar Cervantes, quien realmente actuaba como testaferro del alcalde mayor, por el remate de las mercancías ascendió a 5.090 pesos y 6 reales, tal y como se observa en la Tabla 2. La tercera parte correspondiente al rey, según las directrices de Andrade, que debía depositarse en la Real Caja, se calculó en 1.696 pesos. Por último, los gastos generados durante el proceso de rescate del bergantín -por su conducción hasta Jalapa, el pago de salarios de las personas que participaron en el mismo, los gastos de almacenaje de las mercancías y otros gastos inexcusables-, alcanzaron los 1.570 pesos $^{28}$.

\begin{tabular}{|l|c|c|c|}
\hline \multicolumn{1}{|c|}{ GÉNERO } & CANTIDAD & PRECIO & TOTAL \\
\hline Pipas de aguardiente & 12 & 130 pesos & 1.560 pesos \\
\hline Rejas de arar & 470 & 12 reales & 705 pesos \\
\hline Clavazón & 32,5 quintales & 11 pesos el quintal & 357,5 pesos \\
\hline Resmas de papel & 41 & 6 pesos & 246 pesos \\
\hline Hierro & 204 quintales y 1 arroba & 10 pesos el quintal & 2.042 pesos y 5 reales \\
\hline Herraduras & 173 docenas & 6 reales & 129 pesos y 6 reales \\
\hline Botijuelas de aceite & 10 & 5 pesos & 50 pesos \\
\hline & & & $\mathbf{5 . 0 9 0}$ pesos y $\mathbf{6}$ reales \\
\hline
\end{tabular}

Tabla 2: Remate en almoneda de los géneros rescatados del bergantín. Fuente: Elaboración propia en base a los datos consultados en $\mathrm{AGI}^{29}$.

La actuación de Alonso Felipe de Andrade parecía, cuanto menos, ejemplar. Es más, en el propio interrogatorio de testigos realizado durante la residencia pública del alcalde mayor, algunas de las personas cuestionadas acerca de su gestión con respecto al rescate del bergantín hicieron referencia a su impoluta forma de proceder. Así, Juan Bautista Merchán, indicó que Andrade había decomisado parte del cargamento por venir fuera de registro y que posteriormente se había vendido y rematado todo en pública almoneda, y su procedido e importe lo había aplicado a "Su Majestad". En esa misma línea testificó Benito Carrillo, quien afirmó que había oído decir "que lo que se había enterado en la Real Caja fueron 1.500 pesos" como parte correspondiente a la Corona derivado del remate de los géneros confiscados ${ }^{30}$. Incluso, algunas de las autoridades indias del pueblo de Jalapa que fueron interrogadas en dicho juicio, entre ellos el gobernador Domingo López y el alcalde Pascual de Luna, confirmaron el buen hacer del alcalde mayor en las diligencias realizadas con respecto al auxilio del navío ${ }^{31}$.

Sin embargo, no todos se mostraron conformes con la actuación del gobernante. De hecho, los alegatos realizados por algunas de las personas que participaron en el

\footnotetext{
${ }^{27}$ AGI, Escribanía de Cámara, 233B, Cuaderno 1. Remate de los bienes descaminados del bergantín y cuenta de lo obtenido en dicho remate. Jalapa, 28 de noviembre de 1705.

${ }_{28}$ AGI, Escribanía de Cámara, 233B, Cuaderno 1. Relación de gastos generados en el rescate del bergantín. Jalapa, 6 de diciembre de 1705.

29 lbídem.

30 AGI, Escribanía de Cámara, 233B, Cuaderno 1. Interrogatorio de testigos españoles en la residencia pública del alcalde mayor Alonso Felipe de Andrade. Tacotalpa, 27 de octubre-6 de noviembre de 1706.

${ }^{31} \mathrm{AGI}$, Escribanía de Cámara, 233B, Cuaderno 1. Interrogatorio de naturales en la residencia pública del alcalde mayor Alonso Felipe de Andrade. Tacotalpa, 8-12 de noviembre de 1706.
} 
salvamento del bergantín y la posterior gestión de las mercancías que transportaba diferían por completo de la versión oficial. En el juicio de residencia de Andrade tres vecinos de la región -el sargento mayor don Andrés Gordillo, el capitán don Juan Rodríguez de la Gala y el colector general don Juan Antonio Garrido- presentaron una petición de capítulos por los abusos y excesos cometidos durante su gobierno, entre los que se encontraba el controvertido proceder del alcalde en el rescate del bajel. En dicha petición, alegaban que el volumen de los géneros recuperados y almacenados en Jalapa era mucho mayor que el inventariado, ofreciendo una lista detallada de los mismos:

"Y dichos géneros son los siguientes: 800 quintales de hierro, en 1.400 barras, 500 rejas de arar, 20 cajones de herrajes, 20 cajones de clavazón gruesa, 28 frascos de azafrán con 8 libras cada uno, 100 libras de canela, 40 bretañas, 26 arrobas de aceite, 140 resmas de papel, 22 pipas de aguardiente, 28 botijas de vino en una pipa y 2 barriles" 32 .

Los argumentos aportados por los testigos interrogados en el capítulo desenmascararon un importante fraude en la actuación de Andrade. Más de una decena de personas aseguraron que la carga extraída del bergantín era mucho mayor en volumen de la que se declaró en el inventario oficial, tal y como sostenían los capitulantes. Uno de los principales testimonios lo encontramos en la persona de Juan Antonio Solano, teniente del partido de la Chontalpa y encargado de acudir personalmente al rescate en primera instancia acompañado de once españoles y mulatos y treinta indios de dicho partido. En su declaración aseveró con gran lujo de detalles la importante cantidad de mercancías que se habían recuperado y que no se registraron en la relación firmada por las autoridades en Jalapa. Revisando los alegatos realizados por los declarantes, coincidentes en la mayoría de los casos, se deduce que los productos acopiados de la embarcación fueron, en esencia, los siguientes:

\footnotetext{
32 AGI, Escribanía de Cámara, 233B, Cuaderno 1. Petición de Andrés Gordillo, Juan Rodríguez de la Gala y Juan Antonio Garrido capitulando al sargento mayor don Alonso Felipe de Andrade por abusos y excesos cometidos durante su gobierno. Tacotalpa, 6 de noviembre de 1706.
} 


\begin{tabular}{|l|c|}
\hline \multicolumn{1}{|c|}{ GÉNERO } & CANTIDAD \\
\hline Hierro & 800 quintales (en 1400 barras) \\
\hline Rejas de arar & 500 \\
\hline Tabaco en polvo & 19 sacos \\
\hline Papel & 150 resmas (40 mojadas) \\
\hline Canela & churla (1 saco de 100 libras) \\
\hline Canela & 30 libras (en una caja de cedro) \\
\hline Clavazón (grandes y pequeños) & 20 cajones \\
\hline Herrajes con clavazón & 20 cajones \\
\hline Aguardiente & 22 pipas \\
\hline Aguardiente & 5 barriles \\
\hline Aceite & 48 botijuelas \\
\hline Anclas & 3 \\
\hline Calabrotes & 3 \\
\hline Azafrán & 28 frascos (8 libras cada uno) \\
\hline Bretañas & 40 \\
\hline Vino & 28 botijas \\
\hline
\end{tabular}

Tabla 3: Inventario de los géneros rescatados del bergantín según las declaraciones de los testigos examinados en la residencia de Alonso Felipe de Andrade. Fuente: Elaboración propia en base a los datos consultados en $\mathrm{AGl}^{33}$.

A todas luces, el alcalde mayor había decidido hacer acopio de una parte bastante considerable de los géneros rescatados en el naufragio para sus tratos y negocios personales. Tanto los capitulantes como otros testigos (entre ellos los capitanes don Francisco Pérez y don Pedro Arrivillaga) manifestaron que el montante total de lo recobrado ascendía a 30.000 pesos, una cifra muy superior a los 5.090 pesos y 6 reales que los productos rematados por Andrade habían alcanzado en la subasta. Resulta evidente que el máximo responsable del gobierno en Tabasco había desviado fraudulentamente parte de la mercancía que se había transportado y almacenado en Jalapa justo antes de confeccionar el inventario oficial.

Efectivamente, uno de los testigos, Eugenio Rodríguez de Sodres, vecino de la provincia, indicó que había visto al gobernador abrir dos veces las puertas del mesón y casas reales de Jalapa -donde estaban almacenados los géneros- en aquellos días, "de forma secreta y a deshoras". Igualmente, que había oído decir "que no se sacaba nada de allí sin orden del alcalde".

Aún más, la gran mayoría de las personas interrogadas ofrecieron información minuciosa sobre el paradero de los efectos sustraídos por Andrade. Según varios testigos, la mayor parte del hierro y herraje la había desviado a la provincia de Chiapa utilizando como intermediarios al teniente del partido de Teapa, Carlos Calcáneo de Jímez, y a Sebastián de Quintana, con la orden de hacer entrega de dichos artículos al maestro de campo don José de Velasco.

En su declaración, el propio Calcáneo confirmó la versión planteada por el resto de interrogados, afirmando que:

\footnotetext{
33 lbídem.
} 


\begin{abstract}
"Estando exhibiendo el oficio de teniente de dicho partido de Teapa por el mes de febrero de este presente año le remitió el sargento mayor don Alonso Felipe de Andrade [...] por dos ocasiones porción de hierro y unos cajones de herraje, papel y otras cosas, que no sabe lo que era ni la cantidad de hierro, que no se puede acordar. $Y$ que serían las mulas que lo cargaron el primer viaje como 30 , y el segundo como hasta 60 mulas. Que le dio orden para remitirlo al pueblo de Chiapa de indios, a entregar al maestro de campo don José de Velasco. Y solo corrió este declarante con la remisión de dichos géneros y no con otro expendio alguno. Y antecedente sabe remitió con Sebastián de Quintana otra porción a entregar al dicho, en dicho pueblo. Y esto lo supo del dicho Sebastián de Quintana porque le pidió avío para sacarlo fuera y le dijo era de cuenta de dicho sargento mayor [...] y lo iba a entregar a dicho maestre de campo. Y dichos géneros sabe eran de los del bergantín que naufragó en la costa de esta provincia"34.
\end{abstract}

Igual de reveladora resultó ser la confesión de Quintana, en la que aseguró que Alonso Felipe de Andrade lo había enviado a la provincia de Chiapa "con 100 barras de hierro y 30 resmas de papel, 50 rejas de arar y 2 zurrones con 80 herrajes de mula cada uno [...], 6 resmas, 12 libras de canela, una frasquera de vino y otra de aguardiente", con el fin de hacérselo llegar todo a José Velasco. Además, afirmó que el alcalde mayor le había prometido por el trabajo de conducir y vender los productos 5 cargas de cacao, y que a su regreso solamente le había dado 2 cargas. Por último, ofreció cifras concretas de las ventas realizadas:

"Habiendo vendido resma de papel a 23 pesos y la libra de canela a 15 pesos, la frasquera de aguardiente a 45 pesos y por el mismo precio el vino, y el herraje lo vendía el dicho maestre de campo a 9 reales cada uno. También dice que vendían al dicho maestre de campo algunos quintales de hierro a 36 pesos el quintal, y algunas rejas a 7 pesos cada una"35.

Con respecto a las pipas de aguardiente y la clavazón, el teniente del partido de la Chontalpa, Juan Antonio Solano, entre otros, ratificó que habían sido conducidos hasta Veracruz en la balandra del maestre Miguel Alfonso del Manzano para ser entregados a don Francisco de Aguirre Gomendio, su correspondiente en dicha ciudad.

Tampoco estuvo exenta de polémica la almoneda y remate de los productos que se quedaron en Jalapa. $Y$ es que varios testigos denunciaron las irregularidades en su proceso, tanto en la publicación de los pregones como en las propias pujas. Así, el capitán Francisco Pérez vio coartado su propósito de subastar, ya que pese a haber realizado una oferta superior (15 pesos) a la del capitán Diego Cervantes (10 pesos) por cada quintal de hierro, su concurso no fue admitido por el teniente general Pedro Álvarez Miranda, responsable de dicho remate, adjudicándoselo a

\footnotetext{
34 Todas las citas anteriores corresponden al siguiente documento, AGI, Escribanía de Cámara, 233B, Cuaderno 1. Interrogatorio de testigos realizado en la capitulación presentada por el sargento mayor don Andrés Gordillo, el capitán don Juan Rodríguez de la Gala y don Juan Antonio Garrido, al juez de residencia contra el sargento mayor don Alonso Felipe de Andrade. Tacotalpa, 9-25 de noviembre de 1706.

${ }^{35}$ AGI, Escribanía de Cámara, 233B, Cuaderno 1. Declaración de Sebastián Quintana en el proceso de capítulos puestos a don Alonso Felipe de Andrade en su residencia. Barra de Tabasco, 2 de noviembre de 1706 .
} 
Cervantes pese a haber ofrecido una cantidad menor. Es posible que el estar actuando como testaferro del alcalde mayor en la almoneda pública le ayudase a ganar la puja ${ }^{36}$.

Por si fuera poco, las averiguaciones realizadas por el juez de residencia, Mateo de Reigadas Agüero, confirmaron las acusaciones hechas por los capitulantes: el alcalde mayor se había quedado con los 1.696 pesos aplicados al erario en la almoneda pública pues, aunque constaba un ingreso de dicha cantidad en la "Real Caja" de su cargo con fecha de 30 de noviembre de 1705, finalmente no había remitido dicha cantidad al Tribunal Mayor de Cuentas ${ }^{37}$.

\section{Las consecuencias de la interesada gestión del naufragio}

La irregular actuación de Andrade en las labores de rescate del bergantín no difería mucho de las prácticas corruptas que los gobernantes tabasqueños llevaban cometiendo durante años. Las particulares condiciones de "frontera" 38 de la región, el amplio poder que aglutinaban los alcaldes mayores y el escaso control al que estaban sometidos -teniendo en cuenta la lejanía de la provincia con respecto a los centros de poder-, fueron importantes acicates para que los regidores de Tabasco perpetraran todo tipo de abusos y excesos y manejaran la gestión de aquel territorio velando casi en exclusiva por sus intereses personales, a costa de sus habitantes $y$, en ocasiones -como el caso que nos ocupa- de la propia Corona ${ }^{39}$.

La forma de proceder de Alonso Felipe de Andrade en lo relativo al naufragio del barco y al indebido aprovechamiento de su mercancía y, por extensión, a la controvertida administración de su gobierno, suscitó múltiples quejas por parte de los vecinos y naturales de la provincia. La situación, como acabamos de referir, no les resultaba para nada desconocida. Es más, apenas unos años antes, en mayo de 1701, la frustración de la población indígena había cristalizado en una carta enviada al rey, firmada por los indios del partido de Cunduacán, para quejarse de lo mal administrada que estaba la región e implorar al rey que actuase contra las irregularidades cometidas por los alcaldes mayores. En la misiva, además de dar cuenta de los abusivos repartimientos de géneros que realizaban, también hacían referencia a toda suerte de excesos y arbitrariedades cometidas por dichos gobernantes. Igualmente, en su escrito solicitaban la concesión de un cacique general "por no tener persona a quien volver los ojos ni quien nos defienda en

\footnotetext{
36 AGI, Escribanía de Cámara, 233B, Cuaderno 1. Interrogatorio de testigos realizado en la capitulación presentada por el sargento mayor don Andrés Gordillo, el capitán don Juan Rodríguez de la Gala y don Juan Antonio Garrido, al juez de residencia contra el sargento mayor don Alonso Felipe de Andrade, cit.

37 AGI, Escribanía de Cámara, 233B, Cuaderno 1. Sentencia tocante a los capítulos interpuestos al alcalde mayor Alonso Felipe de Andrade en su juicio de residencia. Tacotalpa, 20 de diciembre de 1706.

${ }^{38}$ El concepto frontera adquiere en la región de Tabasco su máxima expresión durante el periodo colonial. Ubicada en la parte suroeste de la península de Yucatán, a nivel institucional estuvo siempre en el límite entre la Audiencia de México y la de Guatemala, mientras que en lo eclesiástico fluctuó entre el obispado de Yucatán y el de Chiapa.

39 Para conocer en profundidad el funcionamiento de la alcaldía mayor de Tabasco a nivel gubernativo y la controvertida gestión de la misma por parte de sus regidores puede consultarse la monografía MORENO AMADOR, Carlos. Gobernar bajo sospecha. Op. cit.
} 
nuestros pleitos, ni quien se duela de nuestros trabajos, ni abogado que abogue en nuestras causas" y de un escribano "porque el que tiene la provincia es uña y carne con los alcaldes mayores y no fenece pleito nuestro que se pone en su mano, no hace más que lo que el alcalde mayor quiere" 40 .

En los años siguientes, pese a las continuas quejas de los vecinos de Tabasco, la situación no mejoró demasiado. De hecho, fueron muchos los agraviados por Andrade durante su periodo de gobierno por sus controvertidas actuaciones, ya que, no contento con la malversación y el fraude cometido con los géneros recuperados en el bergantín y, por consiguiente, con el desfalco a la Real Hacienda, -al no declarar ni ingresar todo lo confiscado-, el alcalde también consiguió importantes réditos gracias a los continuos abusos cometidos contra los naturales de la región.

En esa tesitura, es lógico entender que su juicio de residencia no fuese nada placentero para sus intereses ${ }^{41}$. Mateo de Reigadas, encargado de ejecutarlo como juez -siendo además su sucesor en el cargo-, tras revisar las quejas y demandas de los vecinos sobre su forma de proceder comenzó una verdadera cruzada contra Andrade. El resultado de las pesquisas realizadas por Reigadas resultó bastante desfavorable para el gobernador. Tras los pertinentes interrogatorios y averiguaciones, y después de haber intentado que el residenciado se defendiese presentando descargos, el 20 de diciembre de 1706 el juez emitió la sentencia relativa a los cargos que se le habían imputado tras la querella de Andrés Gordillo, Juan Rodríguez de la Gala y Juan Antonio Garrido. La consecuencia más inmediata fue, sin duda, el embargo de todos sus bienes y el inicio de una vigilancia permanente compuesta por seis hombres de guardia a las puertas de su casa, ante el recelo de un posible intento de fuga, considerando el duro veredicto que se aproximaba ${ }^{42}$.

Finalmente, el dictamen se concretó en la imputación de diez cargos con sus correspondientes penas. El octavo de ellos se refería al comercio ilícito y fraudulento que el alcalde mayor había efectuado con los productos rescatados del bergantín que naufragó en las costas de Tabasco cuando iba en dirección a Veracruz, los

\footnotetext{
${ }^{40} \mathrm{AGI}$, Escribanía de Cámara, 233B, Cuaderno I. Carta remitida al monarca por parte de los alcaldes de los tres pueblos denominados Zimatanes, pertenecientes al partido de Cunduacán, sobre los abusos cometidos por el alcalde mayor. Cunduacán, 4 de mayo de 1701. La carta se incluye en una real cédula que el rey remitió al fiscal de lo civil de la Audiencia de México, el 12 de diciembre de 1703, en la que daba cuenta del recibo de dicha carta de los indios de Tabasco sobre los abusos y excesos que cometían los alcaldes mayores haciéndoles repartimientos de géneros; Dicha real cédula también se localiza en el Archivo General de la Nación de México, Reales Cedulas Originales, vol. 31, exp. 165 y en Indios, vol. 37, exp. 24.

${ }^{41}$ Este trabajo centra su atención, principalmente, en los aspectos relativos al naufragio del bergantín y la gestión del cargamento recuperado que aparecen reflejados en la sentencia de residencia de Alonso Felipe Andrade. Para analizar con más detalle todo lo relativo al juicio de residencia del alcalde mayor puede consultarse el trabajo de MORENO AMADOR, Carlos. Una dudosa gestión: la actuación de Alonso Felipe de Andrade como alcalde mayor de Tabasco (1704-1706). En: CAÑEDO ARGÜELLES FÁBREGA, Teresa (coord.). América, cruce de miradas. Alcalá de Henares: Servicio de Publicaciones UAH; Asociación Española de Americanistas, 2015, pp. 681-706.

${ }^{42} \mathrm{AGl}$, Escribanía de Cámara, 233B, Cuaderno 1. Petición de los demandantes sobre que se asegure con prisiones a don Alonso Felipe de Andrade por riesgo de fuga. Tacotalpa, 12 de diciembre de 1706.
} 
cuales, como ya hemos dicho, utilizó para hacer tratos y obtener granjerías en Chiapas, Oaxaca y Veracruz. La pena impuesta por el juez de residencia a Alonso Felipe de Andrade por tal motivo ascendió a 20.000 pesos.

El fallo completo elevaba dicha cifra hasta los 27.231 pesos, además de establecer una orden de embargo de todos sus bienes e inhabilitarlo para ejercer cargos públicos. Igualmente, lo condenaba a servir a la Corona durante tres años en las islas Filipinas y a pagar las costas y gastos que generase el juicio. Por último, para asegurar la satisfacción de todas las penas que le habían sido impuestas, el magistrado daba orden de que fuese trasladado a la cárcel pública de Tacotalpa y que posteriormente, una vez exhibidas las condenaciones, fuese llevado preso hasta el castillo de Acapulco mientras que el Consejo de Indias y el rey dictaminasen qué hacer con él ${ }^{43}$.

\section{Un giro "inesperado": la decisión del Consejo de Indias}

Después de notificarle la sentencia de la residencia, Reigadas ordenó llevar al alcalde mayor a casa de don Tomás de Mendoza, indio alcalde de Tacotalpa, utilizada como prisión provisional por estar derrumbada la cárcel pública. Sin embargo, pese a las precauciones tomadas por el juez para mantenerlo recluido, la madrugada del 25 de enero de 1707 Alonso Felipe de Andrade consiguió escapar de la prisión. Las averiguaciones hechas por el magistrado sobre cómo se había perpetrado la fuga le llevó a entender, después de escuchar los testimonios de varios vecinos, que el residenciado había contado con la inestimable ayuda de los guardias que lo vigilaban -a quienes había sobornado-, además de contar con el auxilio de los religiosos de la orden de Santo Domingo de la provincia. Estos últimos, a través de fray Manuel Vázquez, fraile en la cabecera de la provincia, habían facilitado una mula a Domingo Picón, vecino de Teapa, para que pudiese acudir hasta la cárcel donde se encontraba Andrade y lo ayudase en su huida. Una vez llegados a Teapa, a cinco leguas de Tacotalpa, a los prófugos se les había unido un mulato con el objetivo de acompañarlos hasta Ixtapangajoya, ya en la jurisdicción de la provincia de Chiapa, donde los esperaba el padre fray Francisco de Trejo con otra montura para agilizarles la evasión ${ }^{44}$.

Unos días después de dictar sentencia en el juicio de residencia, concretamente el 26 de diciembre de 1706, Mateo de Reigadas envió un auto requisitorio al sargento don Juan Antonio Orrí de Oreini y Avilés, capitán de caballos corazas, corregidor y teniente de capitán general de la ciudad de Antequera, en el valle de Oaxaca, solicitándole que hiciese averiguación sobre los bienes de Alonso Felipe de Andrade que, al parecer, estaban en poder de don Agustín Soto. Este último, tras haber sido citado para declarar, aseguró que no poseía bienes ni efectos del antiguo gobernante, aunque sí que ofreció su testimonio sobre el paradero de dichas mercancías, en gran parte pertenecientes al rescate del bergantín:

\footnotetext{
43 MORENO AMADOR, Carlos. Gobernar bajo sospecha. Op. cit., pp. 480-495.

${ }^{44}$ AGI, Escribanía de Cámara, 233B, Cuaderno 1. Auto para que se averigüe el motivo de la fuga de la prisión de Alonso Felipe de Andrade. Tacotalpa, 25 de enero-22 de febrero de 1707.
} 
"[...] que aunque recibió algunos tercios de cacao que le consignó el maestre de campo don José de Velasco Campo, vecino de Ciudad Real de Chiapa, de cuenta de dicho sargento mayor para que lo beneficiase en esta ciudad y su procedido lo pusiese en la de México, en poder de don Julián Osorio, caballero de la orden de Santiago, por no tener corriente en esta ciudad dicho cacao lo hizo pasar a la referida de México, a poder de dicho don Julián Osorio, cumpliendo con la orden que tenía. Y porque aunque asimismo recibió diferentes partidas de hierro consignadas por el dicho maestre de campo y otras de rejas de arar, uno o dos cajones de herraje, un tercio de papel y un cajón de azafrán, de ello vendió algo para pagar diferentes libranzas de dicho sargento mayor y algunos fletes, y lo demás lo remitió a dicho don Julián Osorio, cumpliendo en uno y otro con las órdenes que temía de su dueño"45.

Unos meses después, en marzo de 1707, Carlos de Navía, en nombre de Alonso Felipe de Andrade, entregó en el Real Acuerdo de la Audiencia de México varias peticiones para que fuese la Audiencia y no Mateo de Reigadas quien feneciese su juicio, debido a los grandes perjuicios y agravios que se le habían hecho. Igualmente, declaró "no ser de este juicio la causa del bergantín, por estar radicado en el superior gobierno" 46 .

Un año más tarde, tras estudiar la solicitud, la Audiencia de México tomó la determinación de remitir el caso al Consejo de Indias ${ }^{47}$. Una vez allí, en agosto de 1709, la decisión de dicha institución resultó ciertamente controvertida, pues dictaminó anular el juicio de residencia dirigido por Mateos de Reigadas y Agüero al considerar que podía haber incurrido en algunas irregularidades. Además, se resolvió modificar la sentencia, limitando la condena de Alonso Felipe de Andrade a 900 pesos por todas las reprobaciones que había recibido en el juicio, devolviéndole sus bienes y retirándole la prohibición de ejercer cargos públicos en la administración indiana una vez satisfecha la condena, algo que hizo a los pocos días de haber publicado su dictamen el Consejo.

Para el caso que nos ocupa, por el octavo capítulo, el dedicado al naufragio del bergantín y a la controvertida gestión de su cargamento, el Consejo de Indias "con la precisa circunstancia de la valuación de dichos géneros, de que se infiere el gran fraude que se causaría a su Majestad", lo multaba con una pena de 500 pesos, una cantidad ciertamente irrisoria considerando el desfalco cometido contra la Real Hacienda ${ }^{48}$.

\footnotetext{
45 AGI, Escribanía de Cámara, 233B. Cuaderno 1. Auto requisitorio del juez de residencia enviado a Antequera, valle de Oaxaca, para solicitar al corregidor que averigüe donde se encuentran los bienes de Alonso Felipe de Andrade. Tacotalpa-Antequera, 26 de diciembre de 1706-7 de febrero de 1707. ${ }^{46} \mathrm{AGI}$, Escribanía de Cámara, 233B. Cuaderno 1. Petición de Carlos Navías en la Real Audiencia de México para que sea el Real Acuerdo el que decida sobre el juicio de residencia de Alonso Felipe de Andrade. Ciudad de México, 14 de marzo de 1707.

${ }^{47} \mathrm{AGI}$, Escribanía de Cámara, 233B, Cuaderno 1. Auto del Real Acuerdo determinando que la causa se envíe al Consejo de Indias. Ciudad de México, 12 de marzo de 1708.

48 AGI, Escribanía de Cámara, 233B, Papeles de la residencia de Alonso Felipe de Andrade. Sentencia del Consejo de Indias de la residencia del sargento mayor don Alonso Felipe de Andrade. Madrid, 17 de agosto de 1709; AGI, Escribanía de Cámara, 233B, Cuaderno 1. Auto del Consejo de Indias indicando que se le desembarguen los bienes a Alonso Felipe de Andrade por haber satisfecho las condenaciones. Madrid, 21 de agosto de 1709.
} 


\section{Conclusión}

Pese a recibir en primera instancia una dura sanción en su juicio de residencia por la discutida administración en la mayor parte de las parcelas que le habían sido encomendadas cuando tomó posesión del cargo de alcalde mayor de Tabasco, incluso habiéndose demostrado su interesado proceder en el rescate del navío Nuestra Señora del Carmen y San José y el consiguiente escamoteo cometido contra el fisco, finalmente el sargento mayor don Alonso Felipe de Andrade, bastante bien relacionado con algunos altos cargos de la administración novohispana, conseguía ser absuelto de la mayoría de las condenaciones y salir prácticamente ileso del proceso de residencia.

Sin embargo, no quedaba ahí la cosa, pues durante el propio desarrollo del juicio le fue concedido un nuevo cargo institucional en Veracruz, al ser nombrado sargento mayor del presidio de dicha plaza, el 23 de noviembre de 1707, por el virrey Francisco Fernández de la Cueva Enríquez, X duque de Alburquerque. Una designación nada desdeñable, pues el puerto veracruzano era considerado en ese tiempo como el más importante de la Armada española en la Nueva España ${ }^{49}$.

\section{Bibliografía}

EUGENIO MARTíNEZ, María Ángeles. La defensa de Tabasco, 1600-1717. Sevilla: Escuela de Estudios Hispanoamericanos, 1971.

FERNÁNDEZ DURO, Cesáreo. Naufragios de la Armada Española. Sevilla: Editorial Renacimiento, 2009.

HARING, Clarence Henry. Comercio y navegación entre España y las Indias en la época de los Habsburgos. Ciudad de México: Fondo de Cultura Económica, 1979.

MARX, Robert F. Shipwrecks in the Americas. Nueva York: Dover Publications, 1987.

MORENO AMADOR, Carlos. Una dudosa gestión: la actuación de Alonso Felipe de Andrade como alcalde mayor de Tabasco (1704-1706). En: CANEDO ARGÜELLES FÁBREGA, Teresa (coord.). América, cruce de miradas. Alcalá de Henares: Servicio de Publicaciones UAH; Asociación Española de Americanistas, 2015, pp. 681-706.

MORENO AMADOR, Carlos. Gobernar bajo sospecha. Estrategias del poder y prácticas corruptas en la alcaldía mayor de Tabasco (1660-1716). Sevilla: Editorial Universidad de Sevilla; Diputación de Sevilla; Consejo Superior de Investigaciones Científicas, 2018.

PAJUELO MORENO, Vicente. Naufragio y rescate de la flota y armada del marqués

49 AGI, Escribanía de Cámara, 233B. Certificado del maestro de campo Pedro de Irles Pineda, gobernador de lo político y militar y teniente de capitán general de Veracruz, sobre el magnífico desempeño de Andrade como sargento mayor del presidio, Veracruz, en 1 de abril de 1708. 
del Vado del Maestre, 1691. Anuario de Estudios Americanos. Ene./Jun. 2019, vol. 76, n. 1, pp. 155-175.

PEREZ-MALLAINA BUENO, Pablo Emilio. Naufragios en la Carrera de Indias durante los siglos XVI y XVII. El hombre frente al mar. Sevilla: Editorial Universidad de Sevilla, 2015.

PÉREZ-MALLAínA BUENO, Pablo Emilio. Los hombres del Océano. Vida cotidiana de los tripulantes de las flotas de Indias, siglo XVI. Sevilla: Diputación Provincial de Sevilla, 1992.

Recopilación de Leyes de los Reinos de las Indias. Madrid: Boix, 1841.

ROMERO CASTAÑO, Luis René y PÉREZ DÍAZ, Juan Felipe. Naufragios y puertos marítimos en el Caribe Colombiano. México: Siglo Veintiuno Editores, 2005.

SÉRGIO, António. História trágico-marítima. Narrativas de naufragios da época das conquistas. Lisboa: Sá da Costa Editora, 2008.

SERRANO MANGAS, Fernando. Naufragios y rescates en el tráfico indiano en el siglo XVII. España: Ediciones Siruela, 1991. 